\title{
Short Communication: Case Study on Stock Verification in a Semi- automated Environment with Special Reference to the Library of the Open University of Sri Lanka
}

\author{
M. M. I. K. Marasinghe ${ }^{1}$, A. H. K. Balasooriya ${ }^{2}$, K. M. R. K. \\ Amarasekara $^{3}$, K. H. T. Abeysekera 4 , R. M. Gunasekara ${ }^{5}$ and K. D. \\ Wickramarathne ${ }^{6}$
}

\begin{abstract}
\footnotetext{
${ }^{1}$ Assistant Librarian, The Open University of Sri Lanka

Email: mmmar@ou.ac.lk ID https://orcid.org/0000-0003-3487-5916

Email: hbala@ou.ac.lk ID https://orcid.org/0000-0002-5735-2547

${ }^{3}$ Deputy Librarian, The Open University of Sri Lanka

Email: ramar@ou.ac.lk $\mathbb{D}_{\text {https://orcid.org/0000-0002-8166-9501 }}$

${ }^{4}$ Senior Assistant Librarian, The Open University of Sri Lanka

Email: khabe@ou.ac.lk iD https://orcid.org/0000-0002-1568-210X

${ }^{5}$ Senior Assistant Librarian, The Open University of Sri Lanka

Email: rmgun@ou.ac.lk ID https://orcid.org/0000-0002-7703-997X

${ }^{6}$ Senior Assistant Registrar, The Open University of Sri Lanka

Email: kdwic@ou.ac.lk iD https://orcid.org/0000-0002-6222-0063
}

${ }^{2}$ Acting Librarian, The Open University of Sri Lanka
\end{abstract}

Stock verification is considered as an essential activity for all types of libraries although the libraries face difficulties in managing it with the regular library works. Development of a simple method to carry out the stock verification of less technologically oriented libraries would benefit the libraries in numerous ways. Therefore, the objectives of the present study were to document the stock verification process carried out by the 
library of the Open University of Sri Lanka and to elaborate on the outcomes and challenges of the stock verification procedure carried out by the library of the Open University of Sri Lanka. This will serve as a reference document to libraries that functioned under a semi-automated environment. The study details the procedure followed by the Open University library while employing a minimum of library resources such as library staff, capital, management, etc. The whole process was conducted in 02 phases as; 01) physical verification, which involved extracting required data from each book in the physical collection and identifying obsolete, outdated books and books to be repaired and 02) data comparison with the accession register to identify lost/ missing books. The study also details the outcomes of the process which include deriving a simple method with minimal human and mechanical errors which enables periodically carrying out the process, increasing the quality and the currency of the book collection, enhancing the library staff skills, and the overcoming the challenge of managing the process with minimum staff, who are parallelly carrying out their routine work at the library.

Keywords: Book Collection, Semi-automated Library, Stocktaking, Stock Verification 


\section{Introduction}

Stock verification in libraries is an essential task to ensure the quality of the library collection, verify the availability of each book in the collection, identify obsolete, outdated books for discarding, select damaged books for mending and maintain an active book collection in the library. But libraries find it difficult to carry out this process regularly, as the traditional methods of stock verification are tedious, mechanical, and consume more labour, time, and management. Some libraries used to perform stock verification, section wise or subject wise because of the difficulty in managing their large collections at once with the existing resources.

The study categorized the libraries into 03 categories based on the level of technology adoption using following criteria.

1. Carrying out all the library functions; acquisition, cataloguing, serials management, circulation, reports generation through an Integrated Library Management system (ILMS)

2. Adoption of technology-based security system

3. Management of library books and functions automatically through a technology system replacing the labour with machines

Based on the above criteria, the categories of libraries can be defined as; automated (meeting all above criteria), semi-automated (meeting at least one of the above criteria) and manual (no criteria met). The library of the Open University of Sri Lanka (OUSL) carries out all the library functions through Koha ILMS and no technology-based security system is adopted. The OUSL library holds a rich collection of books covering a wide array of subject disciplines. Management of 
library books including sorting, shelving, organizing shelves, shelf reading are done by the library staff members. Therefore, the Open University library could be defined as a semi-automated library.

The main problem experienced at the beginning of the stock verification was the lack of documented guidelines on the procedure of stock verification of large collections that are maintained in a semiautomated environment. The OUSL library invested a significant amount of time testing several procedures and selecting the best. Since the Koha ILMS has the possibility of verifying the library's stock, the OUSL library made an attempt to try it out, but had to give up due to many practical difficulties and erroneous results. Thus, the current method was selected.

Unavailability of a documented guideline stressed the need of a reference document outlining the entire stock verification process, it's outcomes, and drawbacks which will be beneficial to the library, in carrying out the process periodically. It will also serve as a reference document to other libraries that have not been fully automated, especially for the public libraries of Sri Lanka.

Therefore, this study details the stock verification process carried out by the library of the OUSL under a semi-automated environment. Thus, the objectives of this study were;

- To document the stock verification process carried out by the library of the OUSL

- To elaborate on the outcomes and challenges of the stock verification process of the library of the OUSL 


\section{Review of Literature}

Stock verification is a non-negligible library work even though libraries feel it as an additional burden and daunting task. It produces benefits to the libraries in numerous ways. Stevens (2011) highlighted some of the benefits of stock verification such as placing the collection in correct shelf order, correctly shelving misshelved books, relabeling the incorrectly labeled items, locating previously missing items, making space on the shelves for items acquired in the future, adjusting shelves, reporting holdings, and missing items.

Libraries make its own method of conducting stock verification considering the available resources, size of the library collection, and level of technology adopted. Rani and Nagaraju (2013) noted different methods of stock verification adopted by libraries. These methods are; by accession register, by separate register with accession numbers in consecutive order, by slips containing accession numbers, by numerical counting of documents on the shelves, by shelf-register cards or shelf-list cards, by sample stock verification, by making stock verification as a continuous process, and by using computers and library management software and other automated methods. The selection of one of these methods mainly depends on the level of technology adopted by the library. Kumbhar and Bidve (2016) carried out a study to identify the stock verification methods used by college libraries of Dr. Babasaheb Ambedkar Marathwada University, Aurangabad. The study identified that, physically checking items on shelves with the accession register as the widely used method while shelf list, computer with barcode technique and quota sampling for larger collections were used by few other libraries. 
At present, with the advancement of technology, stock verification becomes a hassle-free, easy, less time-consuming process for the libraries, which are managed under a fully automated environment. Libraries that have adopted RFID technology, primarily carryout stock verification effectively using this technology (Anandhi \& Sarangapani, 2021; Chhetri \& Thakur, 2019; Kanekar \& Azeeza, 2018; Nisha, 2018). Ahmad (2016) was explained in a study that they successfully conducted a complete inventory control with minimal staff efforts and within the shortest possible time using RFID technology. Chaurasiaand Pankaj (2011) have elaborated on the use of the LibSys software to carry out the stock verification of the Central Library, IIT, Delhi.

However, there are many libraries worldwide that are less technologically developed due to some of the constraints. Therefore, having documented guidelines on stock verification related to semiautomated libraries would benefit carrying out stock verifications effectively.

\section{Methodology}

This study reported the stock verification procedure adopted by the OUSL library under a semi-automated environment with existing limited resources. It is not mandatory for the OUSL library to carry out stock verifications periodically, however, as a measure of upgrading the quality of the collection a stock verification is carried out to identify lost, damaged, outdated books and to ensure that the books are located in the right place in the right order and to compare the actual assets along with the records in accession registers.

The case study method was used as the research method. Zainal (2007) stated that "Case studies, in their true essence, explore and 
investigate contemporary real-life phenomenon through detailed contextual analysis of a limited number of events or conditions, and their relationships" (Zainal, 2007, pp. 1-2). The present study involves a close examination of the stock verification process of the OUSL library, which is a contemporary real-life phenomenon. Thus, the case study method was suitable to systematically detail the stock verification process adopted by the OUSL library. The data were mainly qualitative and were obtained from observations and through relevant documents of the OUSL library.

The whole process of stock verification was carried out while the library was kept open for its users and providing all library services as usual. This was identified as a strength of this method in an era where many of the libraries remain closed during the stock verification. The library was divided into two sections and one section was totally opened for library users for their references and stock verification was carried out in the other section.

The process consisted of the following stages.

1. Planning and preparatory stage

2. Preliminary test run

3. Execution

4. Preparation of the Report

1. Planning and preparatory stage:

Planning of the whole process was mainly done with the involvement of senior academic staff members of the OUSL library. The whole process was planned carefully to ensure the minimum level of human and mechanical errors. A coordinator was assigned for the process, and all the other library staff members were divided into groups. 
Each group consisted of a senior academic staff member, information assistants, and library attendants.

According to the accession registers 109,301 number of items had been accessioned at the time of starting the stock verification process. The total book collection was divided into sub-collections, and a group was assigned for each sub-collection. The resources required for the process were determined; library staff members, computers/ laptops, barcode scanners, separators (made using hard boards to place between books to separate verified and non-verified books). A set up was prepared using MS Excel, enabling the automatic appearance of the accession number next to the manually entered classification number when the barcode in the book was scanned using a barcode reader.

\section{Preliminary test run:}

This was done to ensure all aspects of the plan are feasible with the existing resources and to make necessary changes to the plan if required. The stock verification process was conducted for a selected few book racks, and the time taken was estimated. Accordingly, the time period required to complete the whole process was estimated and which was approximately 03 months.

\section{Execution:}

The whole stock verification process consisted of 02 phases.

1. Physical verification- This was to obtain required data from each book of the physical collection and to identify obsolete, outdated books and books to be repaired

2. Compare the data with the accession register to identify lost/ missing books 
Figure 01 provides a holistic view of the procedure executed under phase 01. This procedure was continued till the whole collection was covered. After completing phase 01, a book circulation report, relevant to the physical verification period was generated to identify the books which were issued and returned during the verification period.

All the data were compiled and organized to execute the $02^{\text {nd }}$ phase of the process. The $02^{\text {nd }}$ phase was mainly focused on checking the physical verification data along with accession registers. The main purpose of phase 02 was to identify lost books and update the accession registers and Online Public Access Catalogue (OPAC).

\section{Preparation of Report:}

This was the final step of the stock verification process. A final report consisted of; the procedure followed during stock verification and data on the total number of books available in the collection, number of lost books, number of books for discarding, number of books for repairing, and number of newly added records to the Koha ILMS.

\section{Outcomes and Challenges}

The approach used in conducting stock verification has highlighted some positive outcomes for the library and library staff members. The stock verification of the library was completed successfully with minimum human and mechanical errors. The library was able to establish a simple and applicable method to carry out the stock verification process periodically. 


\section{Figure 01}

Procedure of the Physical Verification done by the OUSL Library

Shelve all the books

Take a book from the assigned section

$\&$ scan accession number to get it to an excel sheet

Once the accession number is appeared in the excel sheet, enter relevant call number
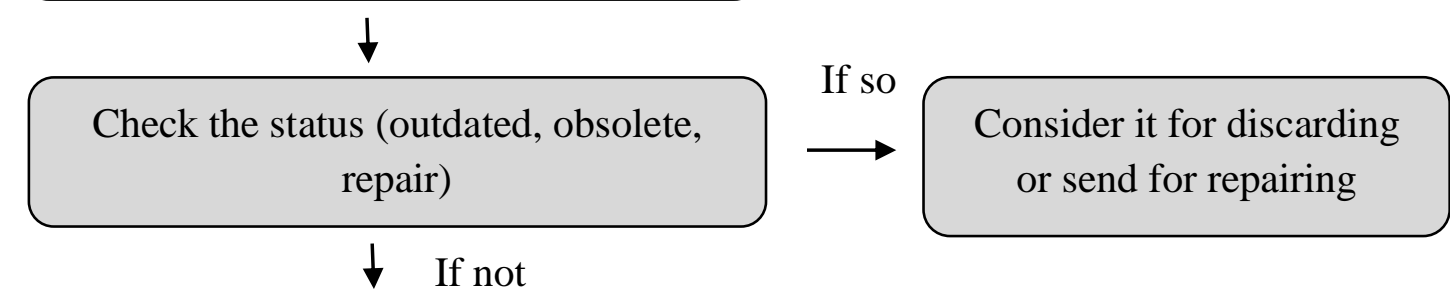

Check the accession number through Koha ILMS

If the record not available

If the record is available

Create a new record through Koha ILMS

Verify all the bibliographic details in Koha record

Mark the verification box of the book with signature

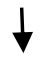

At the end of the day, place a separator between verified and non-verified books 
The process also helped to shelve the books in the correct locations through which the users are able to find the required books within a short period of time. This resulted in making available the OPAC perfectly matched with the physical collection. The process ensured the quality of the library collection by weeding out the obsolete and outdated books.

As for the library staff members, the process contributed to enhancing the skills of the staff members such as multitasking, technical, teamwork, interpersonal skills, etc. It enhanced the team spirit of the library staff members by allowing them to share their knowledge, support others, and work together as a team.

The main challenge of the verification process was managing library staff while they were attending to both routine library operations and stock verification simultaneously. Since the verification process was executed without closing the library, a group of library staff members was allocated to key points of the library to render an uninterrupted library service. The staff members were allocated on a rotational basis in a way that every library staff member gets the opportunity to engage in the stock verification. Completing the process within an allotted time period that was 03 months, was a challenge with the limited resources of the library.

\section{Conclusion}

Periodical stock verification is an essential part of the library management in order to enhance the quality of the library collection by maintaining an active updated library collection. This helps identify the lost and mutilated books, repaired and damaged books, and books to be considered for discarding. There are many ways of conducting stock 
verifications quickly and effectively. The selection of a suitable method for stock verification process depends on the number of books in the collection, library resources, level of technology adopted, availability of capital, etc. Stock verification can be performed in stages, section-wise or subject-wise to avoid closure of the library, which facilitates carrying out routine library services without any interruption.

The study established a step-by-step guide explaining the process of stock verification done by the library of the OUSL. The same process can be simply adopted by the libraries, which are not fully automated. Further, the study pointed out the positive outcomes of the stock verification process such as establishing a simple method to carry out stock verification periodically with minimal mechanical errors, increasing the quality of the book collection, upskilling library staff and the challenge of managing the process while carrying out routine library operations.

\section{References}

Ahmad, H. (2016). RFID technology in Libraries : A case study of Allama Iqbal Library, University of Kashmir. Journal of Indian Library Association, 52(4), 109-120.

Anandhi, C., \& Sarangapani, R. (2021). Implementation of RFID in Arignar Anna Central Library, Bharathiar University, Coimbatore: A Case Study. Library Philosophy and Practice (e-journal). 5571. https://www.proquest.com/openview/89ee3968b95d788877411a00a $\underline{\text { 5e09875/1 } \text { pq-origsite }=\text { gscholar\&cbl }=54903}$

Chaurasia, N. K., \& Pankaj, C. (2011). Library stock management: A case study of stock verification of Central Library, IIT Delhi. 
International Journal of Information Dissemination and Technology, 1(1), 34-39.

https://www.indianjournals.com/ijor.aspx?target=ijor:ijidt\&volume= $\underline{1 \& \text { issue }=1 \& \text { article }=007}$

Chhetri, M., \& Thakur, R. S. (2019). Implementation of RFID

technology in libraries: A case study in UPES library. Library

Philosophy and Practice (e-journal). 2344.

https://digitalcommons.unl.edu/libphilprac/2344/

Kanekar, V. B., \& Azeeza, S. E. (2018). RFID and its applications in libraries. International Journal of Library and Information Studies, 8(1), 137-140. https://www.ijlis.org/articles/rfid-and-itsapplications-in-libraries.pdf

Kumbhar, K. N., \& Bidve, H. (2016). Study of stock verification in college library. Knowledge Librarian, 3(5), 26-35. www.klibjlis.com

Nisha, F. (2018). Implementation of RFID technology at Defence Science library, DESIDOC: A case study. DESIDOC Journal of Library and Information Technology, 38(1), 27-33. https://doi.org/10.14429/djlit.38.1.12351

Rani, S. Y., \& Nagaraju, K. (2013). Librarian's Perceptions on Stock Verification: A Survey of Government Degree Colleges in Andhra Pradesh. Asian Journal of Library and Information Science, 5(4), 3238. http://www.escienceworld.in/index.php/ajlis/article/view/11 Sandu, G., \& Scholastica, U. (2012). Awaking Stock taking practice in academic libraries; The Radio Frequency Identification (RFID) technology. Annual General Meeting of Nigerian Library Association, Proceedings of the $12^{\text {th }}$ Annual Conference, 52-58. 
Journal of the University Librarians Association of Sri Lanka, Vol. 25, Issue 1, January 2022, 8497, Short Communication, DOI: http://doi.org/10.4038/jula.v25i1.8054

Stevens, K. (2011). Taking Stock- The Process and Benefits of Performing a Regular Library Stock take. The ANZTLA E Journal, 06, 2-6. https://doi.org/10.31046/anztla.vi6.209

Zainal, Z. (2007). Case study as a research method. Jurnal Kemanusiaan, 5(1). 1-6. 